\title{
Research on the Application of Internet of Things (IOT) for Urban Gas Industry
}

\author{
Weiqing Zhao \\ Economics and Management School of Wuhan \\ University \\ Wuhan, China \\ e-mail:zhaoweiqing999@g mail.com
}

\begin{abstract}
Internet of things is an important part of the next generation information technology. Also it is a vital development stage of the "informationization" era. The internet of things can connect the traditional urban gas industry to the network information platform. By changing the mode of production, the transformation and upgrading of traditional industries can be finally realized. This paper analyzes the wireless meter reading and remote service, wireless network monitoring and management of the network of gas pipelines on users' side. In this way, it aims to introduce the scheme of network of things now widely used in urban gas industry in China. In the scheme, applying scientific means based on Internet of things deals with effectively control over operation safety cared by all urban gas enterprises. In addition, in big data era, automatic collection of operation data and management data is also realized through Internet of things nowadays, not only laying solid foundation for delicacy management in enterprise, but also providing opportunities for integrating resources, creating new business and finding new profit growth points in traditional enterprises.
\end{abstract}

Keywords-urban gas industry; application; Internet of Things; research; Internet

\section{INTRODUCTION}

With a substantial increase in the popularity rate of gas in China's urban areas, the gas industry in various cities encounters with increasing more problems in the development, such as stable gas supply, safe operation, effective management and quality service. In the management of urban gas industry, the emerging network of things is introduced. And the information on multiple nodes in business process has been collected in real time, which is then processed comprehensively via the servers. In this way, the following businesses can be done: the wireless remote real-time monitoring over pipelines and other gas facilities, the wireless management and dispatching of vehicles and other tools and the wireless meter reading and remote services etc., which may help enhance the management level and operational performance of urban gas enterprises.

\section{BUSINESS CHARACTERIST ICS AND DEMAND ANALYSIS OF URBAN GAS ENTERPRISES}

The core of urban gas enterprises is to supply desired gas resources to various users (e.g. residents, public service industry, business and industry) at reasonable charges.
Gas resources are closely related with national economy and the people's livelihood. To secure an adequate supply, gas enterprises have to sign franchise agreement of urban gas with the government. They have to build and maintain natural gas infrastructures (including portal sites, storage facilities, pipelines, gas station, etc.) in assigned areas. They buy natural gas from upstream supplier and sell it to users within the assigned areas. Moreover, they accept gas application from users, pave corresponding pipelines, install meters, read meters on schedule, charge residents for gas consumption, provide charge voucher, and so on.

Based on above analysis, it can be concluded that informatization of urban gas enterprises mainly covers three systems: (1) gas marketing and meter reading system; (2) monitoring system of gas pipeline network in cities; (3) information-based management system.

\section{INTRODUCTION TO GAS INDUSTRY INFORMATIZATION PROGRAM}

The service chain of urban gas enterprises can be divided into production, transmission, storage, metering, use and marketing. It is characteristic of long transmission distance and wide service range, which increases certain difficulties for urban gas enterprises to achieve highquality, uniform and high-efficiency management, monitoring and services to users. With the continuous development of Internet of Things (IOT), intelligent gas transmission network has attracted wide attentions from urban gas enterprises. IOT can transform and update the original gas network into an intelligent one effectively, thus improving performances of gas enterprises comprehensively. The IOT program of gas transmission includes:

(1) Wireless automatic meter reading system: This gives informatization management on urban gas marketing and meter reading.

(2) Wireless remote monitoring system: GPRS data acquisition modules are used in main monitoring sites (e.g. portal sites and regulating-metering stations). They will cooperate with regional video monitoring and gas leakage monitoring to provide wireless remote monitoring.

(3) Enterprise-based management information system: This is composed of OA, E-mail and vehicle monitoring. The enterprise-based management information system can increase the overall informatization level of gas enterprises. 
The above mentioned three systems are integrated and optimized to get smooth system connections and realize high-efficient automatic operation.

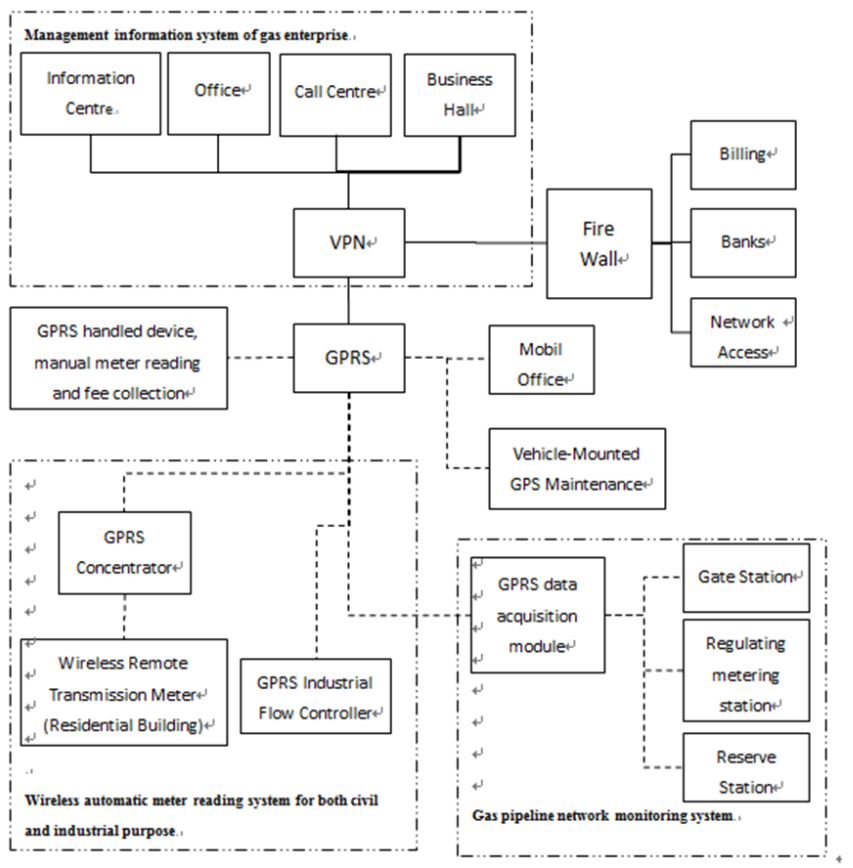

Figure 1. Structure of urban gas industry information program

\section{PROGRAM ANALYSIS}

\section{A. Gas leakage monitoring}

Gas is a flammable and combustible material. Gas leakage will cause very serious consequences. However, it is impossible to make manual management and monitoring comprehensively due to the long transmission distance and wide distribution of gas. Therefore, gas leakage monitoring based on IOT shall be widely applied in gas industry. The gas leakage monitoring shall cover the whole production chain (from production to transmission and to end users) and form an end-to-end monitoring system.

The flammable gas alarm is installed in monitoring sites, while the acousto-optic alarm is installed in the master-control room, reception or other obvious places. These alarms are connected to the system. When there's gas leakage,

(1) The system will send acousto-optic alarm and display the leakage location on the supporting electronic map.

(2) The system will send SMS to related principal and workers. The SMS mainly "calls monitor at the leakage to send gas leakage alarm and asks related staff to handle it promptly".

(3) Staff will report handling results to the monitoring center over the telephone and staff in the monitoring center will clear the alarm.

\section{B. Remote flow monitoring}

Remote flow monitoring system is mainly used in portal sites and regulating-metering stations. It aims to provide real-time monitoring of gas flow and give alarms against abnormalities.
Remote flow monitoring system is connected with gas meters and gives automatic wire less report of conditions of monitored flowmeters to the monitoring center. Flowmeters are monitored by computers and corresponding software in real time at the monitoring center, thus enabling to know metrical information and operation conditions of flowmeters in time. Furthermore, condition number can be output in report through monitoring software for further analysis.

Existing remote flow monitoring system is composed of at least 1 collector, 1 remote transmis sion terminal and 1 set of server software. Remote flow monitoring system is generally installed at service places of flowmeters and mainly monitors flow of single node. The system will collect original data of flowmeters to remote transmission terminal through certain technical means (e.g. pulse and RS485 wire). These data will be integrated by data processing module in the remote transmission terminal and then sent to the monitoring central server (monitoring end) connected to the Internet through GPRS. Monitored ends are managed on the server through monitoring service software. Meanwhile, OPC server is set up to provide OPC services to configuration software. Based on the monitoring interface of configuration software, data can be monitored and analyzed intuitively.

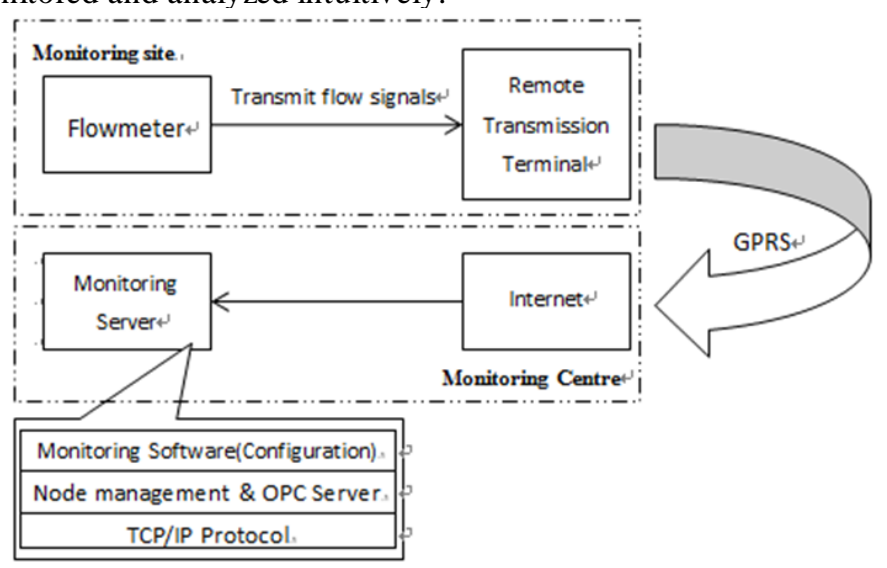

Figure 2. Basic structure of remote flow monitoring system

\section{Remote wireless meter reading}

Gas meters at user end use civil wireless remotetransmission gas meters and industrial wireless flow controller. They are equipped with valve control and battery for power supply. They can be read and controlled wirelessly.

Firstly, a wireless meter reading network shall be constructed in every community by using wireless router. Meter ends are accessed to the network as terminal nodes. All constructed wireless meter reading networks shall be connected to data center of gas enterprises through GPRS concentrator, forming a large network covering all communities. Wireless meter reading is based on the network built by wire less routers and GRPS concentrators. Meanwhile, handheld meter reading device is also available in the remote wireless metering reading system in case of maintenance and possible network failures. Meter reading staff or maintenance personnel will go to communities with the handheld meter reading device or PDA wireless meter reading setting to reach target meters through the wireless meter reading networks or direct 
point-to-point way. Read data will be stored in the wire less device and then input into the wireless monitoring and management information platform of data center of gas enterprises.

The remote user monitoring and management information platform is a network information platform. Database server, management server and application server are set up in the data center. Sales network of gas enterprises is connected to the data center through VPN for related business processing. Additionally, the data center can be connected with banking system through communication front-end processor, which is convenient for users to pay gas fees.

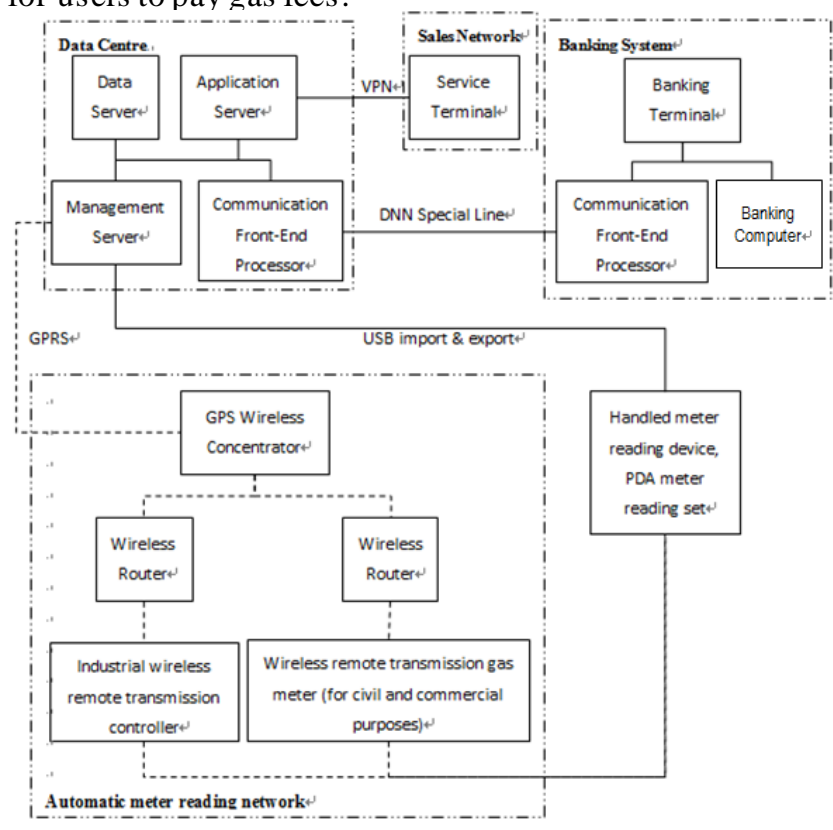

Figure 3. Basic structure of remote wireless meter reading system

This remote wireless meter reading system will bring gas enterprises various benefits:

(1) Remote meter reading causes no disturbances to residents.

(2) Real-time monitoring enables to know operation conditions of meters at any time.

(3) Remote prepayment is convenient for users.

(4) Remote prepayment is more effective in preventing gas stealing and poor supply-marketing problem compared to traditional IC card prepayment.

(5) Compared to wire or carrier remote meter reading system, it requires no additional wire arrangement and is easy to install.

(6) It saves gas enterprises considerable labor cost for meter reading.

(7) Real-time monitoring of meters and business information can prevent staff from private sales of gas resources.

(8) The automatic metering reading and intelligent data analys is improve management level of gas enterprises.

\section{Remote video monitoring}

Since it is necessary to know site conditions clearly for command and dispatch when accident occurred, video monitoring is an important auxiliary mean in many important areas of LNG, such as load stations, portal sites, regulator stations, pipelines and valve box. It can make real-time checks of regional conditions and service conditions of workers. In this way, potential safety hazard can be avoided.

Various transmission modes are optional to video monitoring, such as wire transmission, mobile network transmission, microwave transmission, etc. Video monitoring shall choose the correct mode according to geographical conditions. Besides, different places can choose different storage capacities according to real situations. For example, places requiring front-end monitoring (e.g. portal sites and metering stations) shall have front-end storage and central storage, while rest (e.g. main pipelines and direct-to-home pipelines) shall use network storage.

Existing network video monitoring system that is widely used in gas enterprises consists of front-end collection point, central management platform, client end (including user monitoring center and distributed monitoring points) and bearer network.

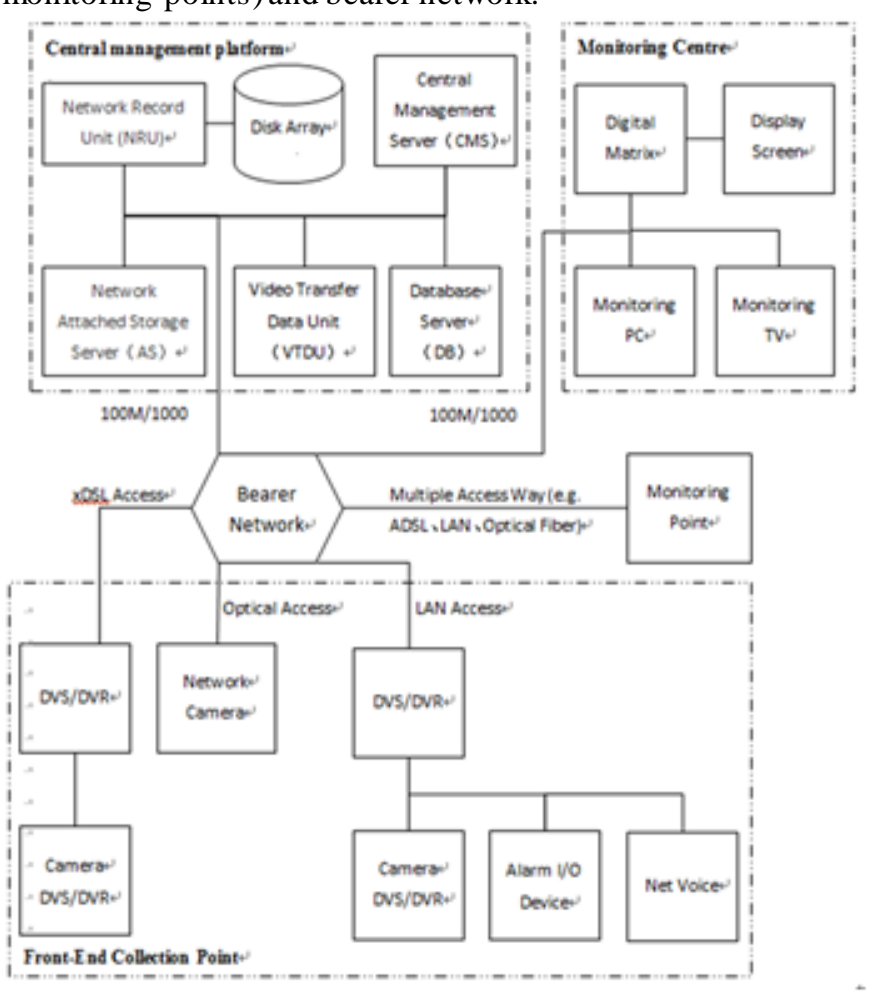

Figure 4. Structure of network monitoring video monitoring

\section{E. Emergency vehicle dispatching}

Vehicle dispatching system uses GPS, internet and GIS technologies to provide vehicle localization, vehicle operation monitoring, vehicle dispatching, management and vehicle information management to gas enterprises. Administrator can make uniform vehicle monitoring, dispatching and management through computer (PC) and the login system. Moreover, the vehicle dispatching system can provide essential statistical statements to guarantee vehicle security to the maximum extent and lower daily production management risks of enterprises.

Administrator could find out the nearest vehicles on the electronic map and make real-time vehicle scheduling to handle alarming conditions. Considering the long gas pipeline and wide coverage, prompt treatment is the key to solve problems. Vehicle dispatching system could not only 
help to check vehicle conditions quickly, but als o make intelligent vehicle scheduling as well as real-time dynamic staffing and material deployment, which is beneficial to make accurate and timely decisions.

- Daily deployment: Setting patrol route for inspection staff and making pipeline distribution be more reasonable and scientific.

- Major engineering deployment: Administrator could implement real-time staffing, vehicle scheduling and resources distribution for major engineering construction according to practical situations.

- Emergency dispatching: At dangerous situations, the monitoring center will determine the corresponding area on the electronic map. The vehicle dispatching system will search vehicles in this area and send command to chosen vehicles to rush to the scene.

\section{F. Other application systems}

(1) Remote valve control

(2) When there's leakage accident, the master-control room could identify the previous pipeline valve of the leakage on the electronic map. The remote valve control system will close this valve, which could avoid poor promptness of manual valve close and thereby prevent bigger accident.

(3) Remote pressure monitoring

(4) The remote pressure monitoring system could provide real-time natural gas pressure of collection points for the monitoring center, which lays foundations for gas enterprises to make data analysis and provides strong support for safety operation and resources allocation of urban gas pipeline network.

\section{CONCLUSIONS}

With the development of information technology, intelligent home systems have begun to enter into thousands of households. Intelligentization of municipal service facilities is an important part of intelligent home system. In this paper, IOT solution to urban gas enterprises is introduced. Through implementation and deployment of this IOT program, it is capable to make remote fullautomatic networked meter reading, uniform resources management and uniform facility maintenance. Meanwhile, it could facilitate office informatization and management informatization of gas enterprises by making full use of the mobile communication technology. A platform for fullautomatic business processing, service feedback and communication is built.

Moreover, this IOT program provides users with an information system integrating production and management, thus achieving lean management and realtime sharing of service data and production data. On this basis, the IOT program could provide gas enterprises with full data support in decision making with its rich statistical analyses.

This IOT program is of high maturity, easy-tooperation and independent deployment. It is highly appreciated by Chinese urban gas enterprises at present.

\section{REFERENCES}

[1] Su Aijun, Wei Jie. Application of Data Acquisition and Monitoring Technology in Gas Pipe Network Scheduling [J]. Gas and Heat, 2011,31 (2): B24-B28.

[2] K. Sakamura, Challenges in the age of ubiquitous computing: a case study of T-engine - an open development platform for embedded systems, in: Proceedings of ICSE'06, Shanghai, China, May 2006.

[3] Ren Xiaojun, Song Lina. Application Prospects of Zigbee Technology in Remote Wireless Automatic Electric Meter Reading System [J]. Journal of Shanxi Datong University, 2008, 24 (5).

[4] Ai Chao, Fu Huaming. RFID-based Design of Network of Things in Modern Factories [J], Application of Electronic Components, 2007, 9 (12): 43-45.

[5] N. Gershenfeld, R. Krikorian, D. Cohen, The internet of things, Scientific American 291 (4) (2004) 76-81.

[6] I. Vázquez, Social Devices: Semantic Technology for the Internet of Things, Week@ESI, Zamudio, Spain, June 2009.

[7] A. Jules, RFID security and privacy: a research survey, IEEE Journal on Selected Areas in Communications 24 (2) (2006) 381394.

[8] D. Niyato, E. Hossain, S. Camorlinga, Remote patient monitoring service using heterogeneous wireless access net works: architecture and optimization, IEEE Journal on Selected Areas in Communications 27 (4) (2009) 412-423.

[9] A. Ilic, T. Staake, E. Fleisch, Using sensor information to reduce the carbon footprint of perishable goods, IEEE Pervasive Computing 8 (1) (2009) 22-29.

[10] D. Giusto, A. Iera, G. Morabito, L. Atzori (Eds.), The Internet of Things, Springer, 2010. ISBN: 978-1-4419-1673-0.

[11] Yong Xie, HongWei Wang. Things based on automatic storage management system and its application [J]. Logistics Technology, 2007(4):90-93. 